\title{
THE SUBJECT OF THE DRUGS \\ A FOCUS IN THE CONSTITUTION OF THE SENSES OF THE CHEMISTRY IN THE POPULAR KNOWLEDGE
}

\author{
MACHADO JÚNIOR, Iterlandes ${ }^{1} ;$ BENJAMIN, Wilson de Souza ${ }^{2}$ \\ ${ }^{1}$ Escola Estadual Conselheiro Afonso Pena, Rua Joaquina Cândida, 50, Centro, \\ cep 35.774.000, Paraopeba - MG, Brasil \\ * e-mail: imachadojr@yahoo.com.br \\ ${ }^{2}$ Universidade de Uberaba, Instituto de Formação de Educadores, Departamento de Química, \\ Campus Aeroporto, Avenida Nenê Sabino, 1801, Bairro Universitário, \\ cep 38055-500, Uberaba - MG, Brasil \\ *e-mail: wilson.benjamin@uniube.br
}

\section{RESUMO}

Considerando-se as dificuldades observadas no ensino médio, numa escola da rede pública em Paraopeba, Minas Gerais, Brasil, para a análise da evolução conceitual dos estudantes sobre a química das drogas, procurou-se pesquisar como suas idéias podem ser transformadas no processo de ensinoaprendizagem. Pôde-se verificar o quanto a intervenção acadêmica foi capaz de contribuir para a melhoria do processo de ensino-aprendizagem, confirmando a hipótese de que a estrutura de análise e planejamento proposto privilegia a negociação das idéias sobre drogas, afinal todos tem espaço para falar.

Palavras-chave: Drogas, Química Orgânica, Funções

\begin{abstract}
Considering the difficulties observed in high school of the public system in Paraopeba, Minas Gerais, Brazil, for the analysis the students' conceptual evolution about chemistry of the drugs, it was researched that your ideas can be transformed in the process of teaching and learning. It can verify the amount that academic intervention is able to contribute to the improvement of the process of teaching and learning. This confirms the hypothesis that the structure of analysis and planning benefits the negotiation of the ideas about drugs, at last all have space to speak.
\end{abstract}

Keywords: Drugs, Organic Chemistry, Functions

Periódico Tchê Química. Vol. 6 - N. 12 - AGO/2009. Porto Alegre - RS. Brasil. 


\section{Introdução}

Em nossa sociedade, ainda é muito comum a visão que dá a ciência um status hegemônico e superior de saber. Essa visão cientificista é também reproduzida na escola. Diante dessa realidade, muitas considerações sobre o ensino e a aprendizagem de ciências têm sido feitas. Um dos debates sobre essa questão refere-se ao significado de ensinar ciências para a vida de estudantes que habitam um mundo de enorme diversidade cultural (1994 apud Godin e Mól, ano 2008, pág. 3).

Os autores supracitados ainda ressaltam que a partir da década de 1990, os educadores e pesquisadores passaram a questionar essa superioridade epistemológica do saber científico e considerar as relações entre cultura e educação científica. A cultura popular e o conhecimento cultural passaram a serem considerados na orientação dos currículos de ciências. Essas modificações podem advir, segundo os pesquisadores, da perspectiva construtivista como tendência na educação científica, da substituição da perspectiva tecnicista na elaboração dos currículos e da postura crítica em relação à ciência ocidental moderna.

Pomeroy (1994 apud Godin e Mól, ano 2008, pág. 3) apresenta algumas estratégias para a educação científica: explorar as interrelações entre ciência, tecnologia e sociedade dentro do contexto de vida dos estudantes: utilizar recursos locais e problemas locais para as problematizações; utilizar textos que abordem narrativas de descobertas científicas para desmistificar a idéia de ciência pronta e acabada; "desenvolver currículos de ciências em torno de conteúdos científicos que expliquem práticas e técnicas populares" (p. 62, tradução e grifo nossos); desenvolver atividades científicas que não violem as crenças dos estudantes; "explorar as crenças, os métodos, os critérios de validade e sistemas de racionalidade sobre os quais o conhecimento do mundo natural de outras culturas é construído".

Recentes pesquisas têm apontado que drogas e violências são temas em evidência e, embora se tenha falado muito sobre eles, paradoxalmente nunca se silenciou tanto a respeito desse complexo problema, sobretudo no que diz respeito à relação que possuem com os problemas sociais, como por exemplo, as desigualdades culturais e educacionais que os permeiam. Em geral, prevalece uma perspectiva que colabora para reforçar estigmas e preconceitos, o que pode, inclusive, comprometer uma postura preventiva e fortalecer, por conseguinte, uma conduta repressiva. Daí a importância da escola e dos educadores que precisam cada vez mais conhecer a teia de complexidades que os envolvem as medidas que estão ao alcance da instituição escolar em sua missão formadora e educadora (Abramovay e Castro, 2005).

Desta forma, buscou-se romper com o modelo tradicional de ensino de química através de uma postura crítica/social dos conteúdos, a partir da negociação de significados científicos ao redor do tema "A questão das drogas e as funções da química orgânica".

Nesse contexto, a intervenção também é de fundamental importância na formação continuada do professor/pesquisador, pois possibilita refletir sobre o seu próprio trabalho docente; num processo contínuo de construção de conhecimento.

\section{Estudo Preliminar sobre o Planejamento Curricular para o Ensino de Química}

A base do programa elaborado corresponde à Proposta Curricular de Química adaptada às normas dispostas pela Resolução SEE-MG, $N^{\circ} 833$, de 24 de novembro de 2006, da Coordenadoria de Estudos e Normas Pedagógicas, Secretaria de Estado da Educação, MG. Segundo essa proposta, o ensino de química deverá visar à aprendizagem dos conceitos, princípios, teorias e leis desta ciência; à compreensão da natureza e processo de produção desse conhecimento, bem como à análise crítica da sua aplicação na sociedade, numa trajetória que envolva transmissão/assimilação/ reavaliação crítica do conhecimento.

A Lei de Diretrizes e Bases da Educação Nacional (LDB), aprovada em 1996, determina que a avaliação seja contínua e cumulativa e que os aspectos qualitativos prevaleçam sobre os quantitativos. Os alunos são respeitados em sua individualidade podendo observar seus progressos em relação a si próprios, dentro do ritmo de aprendizagem de cada um. Para que a 
avaliação sirva à aprendizagem é essencial conhecer cada aluno e suas necessidades.

De acordo com o documento supracitado, a proposta curricular está organizada em torno dos eixos temática Materiais, Modelos e Energia, estruturando-se em tópicos. Para cada tópico apresentam-se habilidades e seu detalhamento.

Busca-se no Conteúdo Básico Comum CBC de Química (Romanelli at. al., 2007) contemplar aspectos conceituais fundamentais que permitam a compreensão da constituição, propriedades e transformações dos materiais, destacando implicações sócio-ambientais relacionadas à sua produção e ao seu uso.

Para a seleção e organização de conteúdos foram considerados alguns focos de interesse da química que dizem respeito a seus objetos de investigação: as propriedades, a constituição e as transformações dos materiais e das substâncias. De acordo com Santos e Schnetzler (2003), considerando a finalidade da educação básica de assegurar ao educando a formação indispensável ao exercício da cidadania, é importante que a base curricular comum contemple, articuladamente com os eixos do conhecimento químico mencionado (propriedades, transformações e constituição), a abordagem de temas sociais que propiciem ao aluno o desenvolvimento de atitudes e valores aliados à capacidade de tomada de decisões responsáveis diante de situações reais.

Assim sendo, a contextualização no currículo da base comum poderá ser constituída por meio da abordagem de temas e situações reais de forma dinamicamente articulada, que possibilitem a discussão, transversalmente aos conteúdos e aos conceitos de Química, de aspectos sociocientificos concernentes a questões ambientais, econômicas, sociais, políticas, culturais e éticas (Zanon et. al., 2008).

\section{Desenvolvimento}

Esta intervenção foi realizada em três turmas do $3^{\circ}$ ano do ensino médio em uma escola da rede pública de Paraopeba (MG), com aproximadamente 150 alunos.

É possível que a discussão sobre a química das drogas, dos medicamentos e suas implicações sociais contribua para a promoção de alternativas importantes na prevenção do uso indiscriminado destes. Diante disso, os alunos foram desafiados a resolverem algumas questões pertinentes ao tema abordado; em grupos de cinco ou seis, de modo a dar oportunidade a todos de participarem ativamente dos debates, além de me informar o quanto estão entendendo sobre 0 assunto que está sendo discutido.

Durante as aulas expositivas foram usadas algumas transparências, para que os estudantes não ficassem muito presos ao quadro. Sempre que necessário, era empregado modelos moleculares, para que eles tivessem uma melhor compreensão espacial da geometria molecular e sua influencia na reatividade das espécies químicas. A metodologia utilizada baseou-se em temas teórico-práticos relacionados ao cotidiano dos alunos visando uma situação pedagógica criada pela exposição prática com materiais alternativos, de forma que pudesse criar obstáculos a serem superados.

As atividades experimentais também foram planejadas visando possibilitar a integração de saberes do Cotidiano e da Ciência, permitindo melhorar o pensamento químico sobre o meio. O experimento em si já permite a formação de inúmeras idéias nos estudantes, sendo importante que essas idéias sejam bem ordenadas e possa transformar-se em conhecimento químico.

Pôde-se verificar através do desenvolvimento desse trabalho, que a negociação do tema supracitado fez-se, ao longo do processo de ensino-aprendizado, um importante instrumento de conscientização sobre os diversos significados para o conceito de drogas e medicamentos, além das possíveis razões para o consumo de entorpecentes e para a automedicação. Ainda, procurou-se ressaltar nos trabalhos apresentados os aspectos químicos desse consumo, sua interação com o organismo e suas implicações psicológicas, sociais e econômicas.

Nas Figuras 1 e 2 são apresentados os diversos tipos de drogas abordados na sala de aula de química, como é conhecida popularmente, seus aspectos físicos, forma de administração e efeitos clínicos (ação no sistema nervoso central e síndrome de abstinência).

Entre as concepções mais freqüentes apresentadas pelos alunos para o conceito de drogas e medicamentos, ressalta-se que "as 
drogas são substâncias que provocam alterações no sistema nervoso, sensação de prazer, anestesia e causa muita dependência. Droga é qualquer composto químico de uso médico diagnóstico, terapêutico ou preventivo que pode levar a dependência, tais como: alucinógenos e excitantes. (...) São vários os motivos para que as pessoas, principalmente jovens, utilizem drogas. Um dos principais motivos é a sensação de prazer que a maioria das drogas causa. (...) O organismo na maioria das vezes fica dependente dela, e esse prazer se transforma em vício. Um bom exemplo se dá nos usuários de cigarros e bebidas alcoólicas pois, são substancias que causam dependência ao atingirem o Sistema Nervoso Central (SNC), deprimindo o mesmo. Outro bom exemplo se dá nos usuários de cocaína. Pelo fato dela ter efeitos estimulantes, a cocaína, as vezes, causa uma sensação de maior inteligência. Esses efeitos se dão por substâncias que atuam no cérebro, os neurotransmissores, que afetam as "mensagens" que se refletem no comportamento. Mas muitos não sabem das conseqüências do uso freqüente ou abusivo. (...) O primeiro efeito, normalmente é psicológico, pois o usuário pode ficar agressivo quando está sem a droga, fazendo de tudo para conseguir mais droga, o que causa uma segunda conseqüência: a econômica. A pessoa faz de tudo para conseguir dinheiro, inclusive vender seus pertences. Devido ao uso freqüente, o organismo fica alterado, ou seja, o terceiro efeito. A droga, em sua maioria, destrói neurônios, causam câncer, deterioram o organismo de forma geral, levando a morte. É de extrema importância que os pais estejam atentos ao comportamento dos filhos, eles devem ser mais presentes. A escola também deve trabalhar mais com o tema "Drogas"; a disciplina de Química pode levar os adolescentes a conhecer melhor as drogas e seus efeitos. Logo, os pais e a escola são importantes parceiros na prevenção das drogas."

Sobre as diferenças entre drogas e medicamentos, eles acreditam que os medicamentos têm a sua fórmula alterada para beneficiar a saúde humana, mas quando mal empregados podem ter o mesmo efeito negativo. Para os alunos "os medicamentos são drogas usadas de maneira correta que, sob recomendação médica, ajuda no tratamento de doenças. Já as drogas não possuem nenhum tipo de benefício. $A$ automedicação está presente no nosso dia-a-dia, sem mesmo percebermos já estamos fazendo o uso de remédios sem recomendação ou receita médica. (...) Um exemplo bem claro disso é que um amigo meu, tornou-se viciado em calmantes, quando ele não fazia o uso dessas pílulas para dormir, ele ficava nervoso, violento e muitas vezes quebrava tudo que via pela frente. Um detalhe importante: ele fazia a automedicação só pelo simples fato do seu pai ser médico, ele pensava que entendia tudo sobre remédios. Portanto, a automedicação em vez de ajudar pode é atrapalhar."

As discussões com um policial militar, também puderam trazer para a sala de aula algumas questões importantes, como por exemplo: Como amenizar a influência dos jovens no tráfico de drogas? No discurso produzido em sala de aula ressalta-se que "a observação com a movimentação de pessoas diferentes no seu bairro, na sua rua, no seu vizinho é preciso. (..) Não se deve ter medo mas, sim, denunciar prá que não chegue dentro da sua casa. Em um certo bar perto da minha casa os drogados se reúnem depois da meia noite para se drogar. Quando chegam a polícia, eles arrumam um jeito de se safar e a policia não encontra nada. A maior dificuldade de um usuário de drogas é aceitar que isso é um problema e buscar ajuda. Para ajudá-lo, a opção é a indicação de um tratamento específico: psicológico, psiquiátrico, médico, etc. Juntamente com a ação da família na reabilitação do usuário, os resultados serão satisfatórios, caso contrário, a sua saúde ficará debilitada, muitos transtornos poderão surgir, até um final trágico como a morte. Além de ajuda familiar, projetos devem ser desenvolvidos na comunidade para dar assistência aos usuários mantendo uma boa relação com a sociedade. (...) Poderia ser feito aqui no bairro uma casa de apoio ao dependente de drogas, para que assim esses usuários possam falar o que os levou a usar drogas e que possam estar buscando ajuda profissional. (...) Infelizmente, essa raiz de todo mal está longe de ser cortada. Nada têm sido feito para ocupar os jovens, como: jogos e artesanato. (...) Entretanto, a primeira atitude a ser tomada para que o usuário de drogas saia dessa "vida" depende de sua própria vontade de parar. Nada adianta agir com brutalidade, isso só o faz ficar mais agressivo. É uma difícil questão de conscientização. Um exemplo que conheci bem foi de um garoto de 20 anos, que começou cedo nessa vida. Sua mãe tentou de todas as formas o levar para outro caminho. Ele roubava 
muito, foi preso várias vezes e sua mãe sempre tentando resgatá-lo mas, nada adiantou. Ele ficava sempre preso e sua mãe o visitava com freqüência, até que um dia ela não agüentou mais e veio a falecer. No dia de seu velório ele não pode ao menos se despedir da mãe pois, estava preso e sem apoio de ninguém."

Houve também a apresentação de uma peça teatral, não prevista no planejamento, abordando a história de uma jovem que, sem a atenção da família se deixou levar pelo mundo das drogas. Ressaltaram-se seu relacionamento com a mãe, com sua nova amiga, seu sofrimento e sua recuperação.

A Figura 3 refere-se aos trabalhos realizadas na sala de aula de química.

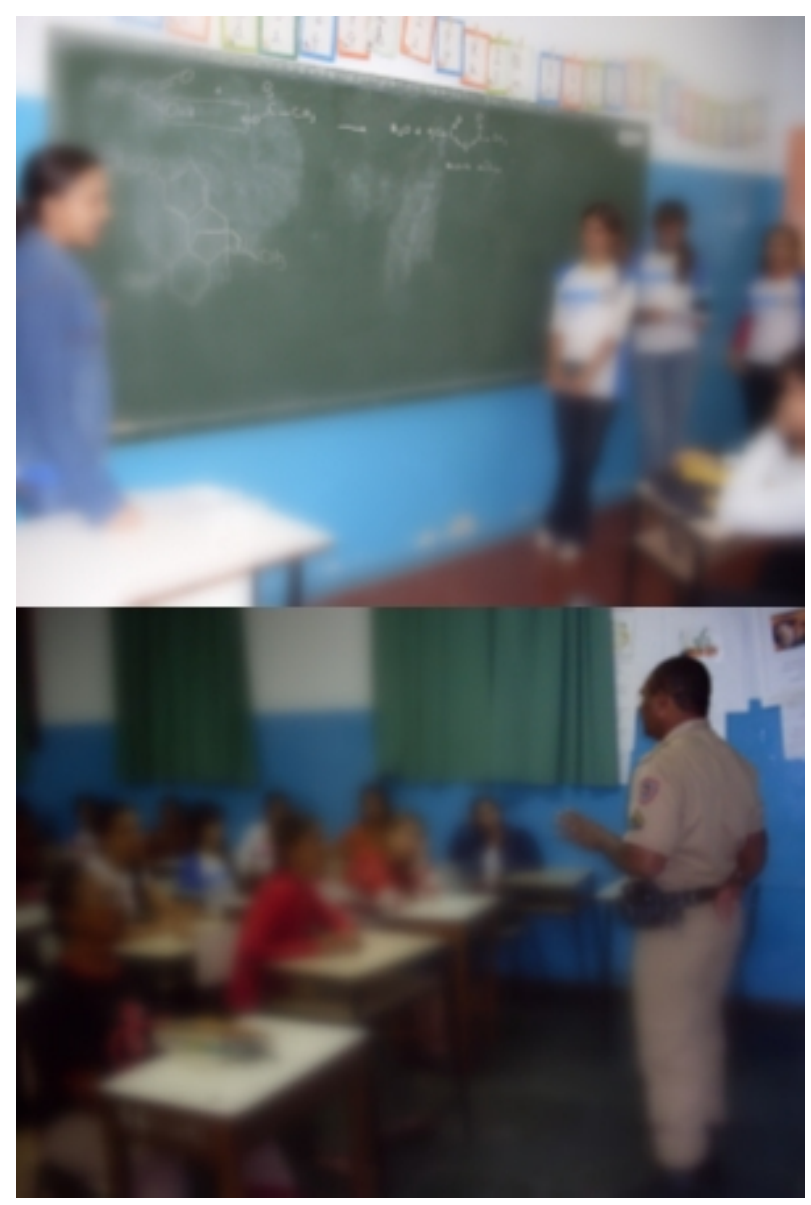

Figura 3 - Apresentação de trabalhos.

A sala de aula transformou-se num importante espaço de discussão entre alunos e professor fazendo com que as funções da química orgânica realmente funcionassem na prevenção do consumo de drogas e do emprego indiscriminado de medicamentos ao imergirem criticamente nesse problema que castiga a nossa sociedade, propondo ainda novos caminhos para combater esse mal.

\section{Conclusões}

Apesar de sua importância, os aspectos culturais relativos a origem e consumo de drogas foram pouco explorados requerendo maior atenção em trabalhos subseqüentes. A falta de uma vivência mais enriquecida do aluno também acarreta uma maior dificuldade de leitura e interpretação dos textos científicos. É necessário, primeiramente, resgatar destes alunos a disposição de ler o material didático. Nesse sentido, os textos científicos requerem maior contextualização do professor/pesquisador e, por parte dos alunos, boa vontade em querer aprender.

As dificuldades para ensinar Química se acentuam em turmas maiores, estas por sua vez são mais heterogêneas no que se refere às diferenças de idade. Observa-se que alunos mais velhos e por tanto, fora da idade escolar são mais dedicados, no entanto apresenta menor rendimento acadêmico.

A experimentação nas aulas de química (por exemplo, a construção de um bafômetro e/ou um fumômetro com materiais alternativos) tornou-se inviável devido à carência dos recursos mínimos para o trabalho docente. Nesse caso, deve-se repensar nas contribuições de uma reativação do laboratório de ensino para a escola, mesmo com a contribuição de materiais caseiros, por toda a comunidade acadêmica.

Para Chassot (2003), a análise conjunta, de forma dialógica, dos diferentes significados atribuídos ao conhecimento e as diferentes formas de construção deste conhecimento, apresenta-se como uma alternativa importante no processo de alfabetização científica. Diante disso, pergunta-se: Como os conhecimentos, não apenas dos saberes, mas também das técnicas e práticas populares sobre a química das drogas podem ser transformadas no processo de ensino/aprendizagem, por alunos do Ensino Médio?

É possível que o um conjunto de categorias propostas por Campos (2002), aliado à rota metodológica elaborada por Pinheiro (2007), 
possa nos auxiliar na interpretação dos saberes, técnicas e práticas de um grupo de exdependentes, buscando estabelecer, suas relações com o conhecimento químico escolar.

Inicialmente, sugerimos uma discussão na sala de aula sobre a origem, a classificação, a implicação social e econômica do consumo de entorpecentes, assim, como relatamos através deste. Em seguida, o trabalho de campo poderá ser feito com base na etnografia descrita pela antropologia cultural. Espera-se, assim, evidenciar as possíveis relações entre os saberes constituídos por um grupo social, com os conhecimentos dos alunos e da Química.

\section{Referências Bibliográficas}

1. ABRAMOVAY, M.; CASTRO, M.G. Drogas nas escolas: versão resumida. Brasília: UNESCO, Rede Pitágoras, 2005. $143 \mathrm{p}$.

2. BRASIL. Proposta de Diretrizes para a Formação de Professores da Educação Básica, em Cursos de Nível Superior. Ministério da educação. Brasília, 2000.

3. CAMPOS, M.D. Etnociência ou etnografia de saberes, técnicas e práticas? IN: AMOROZO, M.C.M., MING, L.C.; SILVA, S.M.P. Métodos de coleta e disciplinas correlatas. Anais, Rio Claro: UNESP, 2002. p.47-92. Disponível em: <http://www.sulear.com.br/texto02.pdf> Acesso em: jun 2009.

4. CHASSOT, A. Alfabetização Científica: Questões e Desafios para a Educação. $3^{a}$ ed. Ijuí: Editora UNIJUÍ, 2003.

5. GONDIM, M.S.C. e MÓL, G.S. Saberes Populares e Ensino de Ciências: Possibilidades para um Trabalho
Interdisciplinar. Química Nova na Escola. São Paulo, n. 30, p. 3-9, nov. 2008.

6. PINHEIRO, P.C. A interação de uma sala de aula de química de nível médio com o hipermídia etnográfico sobre o sabão de cinzas vista através de uma abordagem socio(trans)cultural de pesquisa. 2007. Tese (Doutorado) Faculdade de Educação, Universidade de São Paulo, São Paulo, 2007. Disponível em:

http://www.teses.usp.br/teses/disponiveis/ 48/48134/tde-14112007-150443/> Acesso em: jun 2009.

7. ROMANELLI, L.I.; DAVID, M.A.; LIMA, M.E.C.C.; LEAL, M.C.; SILVA, P.D.S. Conteúdo Básico Comum - CBC (Química - Ensino Médio). In: Centro de Referência Virtual do Professor. 2007. Disponível em: $<$ http://crv.educacao.mg.gov.br/sistema_c rv/banco objetos crv/\%7BB4E56C19D8C8-4DAA-A3D4-2668F6312CDE \%7D_LIVRO\%20DE\%20QUIMICA.pdf> Acesso em: jun 2009.

8. SANTOS, W.L.P.; SCHNETZLER, R.P. Educação em Química: compromisso com a cidadania. $3^{a}$ ed. ljuí: Ed. Unijuí, 2003. 144p. (coleção educação em química)

9. ZANON, L.B.; MALDANER, O.A.; GAUCHE, R.; SANTOS, W.L.P. Ciências da natureza, matemática e suas tecnologias. Brasília: Ministério da Educação, Secretaria da Educação Básica, 2008. 135 p. (orientações curriculares para o ensino médio, v. 2) 


\begin{tabular}{|c|c|c|c|c|}
\hline Tipo da droga & Como é conheciela & Aspectos físicos & Como é aetministraela & Efeitos clínicos \\
\hline Anfeteming & $\begin{array}{ll}\text { - } & \text { Rebite } \\
\text { - } & \text { Ioe } \\
\text { - Speed } \\
\text { - Ecstasy } \\
\text { (MDMA) }\end{array}$ & $\begin{array}{l}\text { - Formas de } \\
\text { cristais } \\
\text { Pó grosso } \\
\text { Cápsulas e } \\
\text { tabletes de } \\
\text { vários } \\
\text { tamenhose } \\
\text { cores }\end{array}$ & $\begin{array}{l}\text { - Cheirada } \\
\text { - Fumada } \\
\text { - Vis Oral } \\
\text { - Injetada }\end{array}$ & $\begin{array}{l}\text { - Taquicardia, } \\
\text { palpitạóes, e } \\
\text { arritmias } \\
\text { - Hipertensäo } \\
\text { - Supressäo do } \\
\text { apetite } \\
\text { - Euforia } \\
\text { - Sedaçăo } \\
\text { - Depressäo } \\
\text { Paranćias e } \\
\text { alucinaçoses }\end{array}$ \\
\hline Cocaine & $\begin{array}{l}\text { - Cradk } \\
\text { - Coce } \\
\text { - Coceetileno } \\
\text { (cocaíne + } \\
\text { álcol) }\end{array}$ & 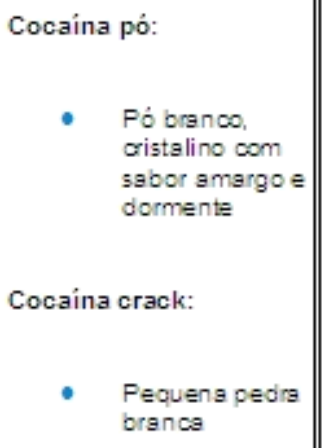 & $\begin{array}{l}\text { - Cheirada } \\
\text { - Fumada } \\
\text { - Injetada }\end{array}$ & $\begin{array}{ll}\text { - Estimulaçăo } \\
\text { do SNC } \\
\text { Dilataça das } \\
\text { pupilas } \\
\text { - Depressão } \\
\text { respiratória } \\
\text { - Paranćia } \\
\text { - Euforia } \\
\text { - Depressão } \\
\text { - Sedaçäo }\end{array}$ \\
\hline Cangbincides & $\begin{array}{l}\text { - Maconhe } \\
\text { - Marijuana } \\
\text { - Haxixe }\end{array}$ & $\begin{array}{l}\text { - Folha seca } \\
\text { - Cigarro } \\
\text { preparado } \\
\text { Líquido viscoso } \\
\text { (óleo de Haxixe) }\end{array}$ & Fumede & $\begin{array}{l}\text { - Aumento do } \\
\text { apetite } \\
\text { - Apatis } \\
\text { Perda da } \\
\text { noçăo do } \\
\text { tempo } \\
\text { Diminuicào de } \\
\text { cordenaçăo } \\
\text { motora } \\
\text { - Tequicardia } \\
\text { - Alucinaçóes }\end{array}$ \\
\hline Acido Lisérgico & LSD & $\begin{array}{l}\text { - Cristal branco } \\
\text { Impregnado de } \\
\text { folha de papel } \\
\text { (micro pontos) } \\
\text { - Cápsula/Tablete }\end{array}$ & Vis orsl & $\begin{array}{l}\text { - Salivaçăo } \\
\text { - Alucinaça } \\
\text { - Dilataçăo da } \\
\text { pupila } \\
\text { - Euforia } \\
\text { - Eleva çào da } \\
\text { temperatura } \\
\text { do corpo } \\
\text { Atacue de } \\
\text { pânico } \\
\text { - Tremores }\end{array}$ \\
\hline
\end{tabular}

Figura 1 - Diversos tipos de drogas abordados nas aulas de química.

Fonte: Maxilab - Laboratório de análises toxicológicas. Disponível em:

<http://www.maxilabor.com.br/teste/tipodedrogas.php> Acesso em: jun 2009. 


\begin{tabular}{|c|c|c|c|c|}
\hline Tipo da elroga & Como é conhecieta & Aspectos físicos & Como é atministrata & Efeitos elínices \\
\hline Opiaceos & $\begin{array}{ll}\text { - Heroina } \\
\text { - Morfina } \\
\text { - Codeína }\end{array}$ & $\begin{array}{l}\text { - Pó branco, } \\
\text { marrom, ou } \\
\text { preto } \\
\text { Injetíveis } \\
\text { - Cápsulas / } \\
\text { tabletes }\end{array}$ & $\begin{array}{l}\text { - Via oral } \\
\text { - Injetada } \\
\text { - Cheirada }\end{array}$ & $\begin{array}{ll}\text { - } & \text { Depressào do } \\
\text { - SNC } \\
\text { - Anslgesia } \\
\text { - Vertigens } \\
\text { - Sedaçào } \\
\text { - Fraqueza } \\
\text { - Euforia } \\
\text { Supressão da } \\
\text { dor } \\
\text { - Náuses }\end{array}$ \\
\hline Benzodiazepinicos & $\begin{array}{ll}\text { - Lexotam } \\
\text { - Lorax } \\
\text { - Valium }\end{array}$ & $\begin{array}{l}\text { - Pó cistalino de } \\
\text { várias cores } \\
\text { - Cápsulas } \\
\text { - Líquidos }\end{array}$ & - Via oral & $\begin{array}{ll}\text { - } & \text { Depressäo } \\
\text { - Sonolêndis } \\
\text { - Diminuiçäo da } \\
\text { anseidgode } \\
\text { - Letargis } \\
\text { - Faciga } \\
\text { - Eoca seca } \\
\text { - Incoordena çào } \\
\text { motora }\end{array}$ \\
\hline Barbitúricos & $\begin{array}{l}\text { - Seconal } \\
\text { - Nembutal }\end{array}$ & $\begin{array}{l}\text { - Pó brancos } \\
\text { - Líquidos } \\
\text { - Cápsulas/ } \\
\text { tabletes }\end{array}$ & $\begin{array}{l}\text { - Via oral } \\
\text { - Injeçäo } \\
\text { intramuscular } \\
\text { - Injeçäo } \\
\text { intravenosa }\end{array}$ & $\begin{array}{l}\text { - Depressäo do } \\
\text { sistema } \\
\text { cardiovascular } \\
\text { - Supressão da } \\
\text { ansiedade } \\
\text { - Anestesia } \\
\text { - Sedaçăo } \\
\text { - Diminuiçäo da } \\
\text { acuidade } \\
\text { visual }\end{array}$ \\
\hline Álcool (etanol) & $\begin{array}{l}\text { - Cerveja } \\
\text { - Vinho } \\
\text { - Conhaque } \\
\text { - Caipininha }\end{array}$ & $\begin{array}{l}\text { - Líquidos em } \\
\text { forma de } \\
\text { bebides } \\
\text { Antissépticos } \\
\text { bucais }\end{array}$ & - Via oral & $\begin{array}{ll}\text { - Intoxicaçăo } \\
\text { - Insonânia } \\
\text { - Diminuiçäo do } \\
\text { controle motor } \\
\text { - Depressä́o } \\
\text { dos reflexos } \\
\text { - Letargia } \\
\text { - Coma } \\
\text { - Morte }\end{array}$ \\
\hline
\end{tabular}

Figura 2 - Diversos tipos de drogas abordados nas aulas de química.

Fonte: Maxilab - Laboratório de análises toxicológicas. Disponível em:

<http://www.maxilabor.com.br/teste/tipodedrogas.php> Acesso em: jun 2009.

Periódico Tchê Química. Vol. 6 - N. 12 - AGO/2009. Porto Alegre - RS. Brasil. 